\title{
Sero prevalence of anti-tissue transglutaminase in patients having sign symptoms of celiac disease: A cross sectional study from Peshawar, Pakistan
}

\author{
Shehryar Ahmad ${ }^{1,2^{*}}$, Naseem Akhtar Gill ${ }^{1}$, Farmanullah ${ }^{1}$, Irum $\mathrm{Naz}^{3}$, \\ Nasir Ali $^{2}$, Muhammadullah Afridi ${ }^{1}$, Naqash Ahmad $^{2}$ and Nihal \\ Ahmad $^{4}$ \\ 1. Rehman college of Allied Health Sciences \\ 2. College of Medical Technology, Bacha Khan Medical College, Mardan-Pakistan \\ 3. National College University System-Pakistan \\ 4. Clinical Technologist at Rahman Medical Institute Peshawar-Pakistan \\ *Corresponding author's email: shery9444@gmail.com \\ Citation \\ Shehryar Ahmad, Naseem Akhtar Gill, Farmanullah, Irum Naz, Nasir Ali, Muhammadullah Afridi, Naqash \\ Ahmad and Nihal Ahmad. Sero prevalence of anti-tissue transglutaminase in patients having sign symptoms of \\ celiac disease: A cross sectional study from Peshawar, Pakistan. Pure and Applied Biology. Vol. 10, Issue 1, \\ pp280-284. http://dx.doi.org/10.19045/bspab.2021.100029
}

Received: 23/06/2020 Revised: 24/08/2020 Accepted: 01/09/2020

Online First: 17/09/2020

\section{Abstract}

Gluten sensitive enteropathy or more commonly known as celiac disease is one of the auto immune disorder affecting $1 \%$ of the individual globally. It is one of the common gastrointestinal disorder in Peshawar, Pakistan and there is scarce of literature available on its prevalence hence this study was aim to determine the seroprevelance of Anti Tissue Transglutaminase (tTG) in patient suspected of celiac dieses and subtype of antibody i.e IgG-IgA contributed towards its seroprevelance. A cross sectional study was conducted on 639 patients having sign symptoms of celiac disease visiting to Rahman medical Institute Peshawar, Pakistan in 2018. Convenient sampling technique were used for selection of samples and screening was done by testing serum Anti tTG IgG and Anti tTG IgA antibody level by Alegria Enzyme linked Immune Sorbent Assay (ELISA) technology. Chisquare test were performed for association between the categorical variable and $p$ value of $<0.05$ was considered statistically significant. Out of total 639 patients, 57 patients were positive for Anti tTG antibodies and the highest count was observed in age group 0 - 20 with frequency of 49 patients. Chi square test reveals no statistically significant difference between gender and seroprevelance of Anti-tTG with a P value of $<0.05$. The seroprevelance of Anti-tTG were high among age ranges from 1 to 20 years. Anti tTG IgG-IgA contribute for screening of celiac disease, however small bowel biopsy is required for confirmation of diagnosis.

Keywords: Antitissue transglutaminase; Antibodies; Celiac disease; ELISA; Seroprevelance Introduction

Celiac disease also known as gluten characterized by both intestinal (diarrhoea, sensitive enteropathy is one of the most common autoimmune disease bloating, constipation) and extra intestinal (anemia, osteoporosis, depression, weight loss) clinical symptoms [1, 2]. Celiac 
disease cases were frequent and still considered uncommon in different parts of world. Gluten a family of protein found in wheat, barley, spelt and rye. The exposure of gluten in those having celiac disease can damage the microvilli by eliciting immune response. Genetic mutations involved in celiac disease are HLA-DQ2 and HLADQ8 a cellular protein which triggers an immune response [3]. Gluten free diet is recommended in order to render the symptoms and healing of intestinal mucosa [4]. The clinical manifestation remains silent or may vary in form of only extra intestinal presentation. In Countries related to European region celiac disease is one of most common encountered disorder affecting 0.5 to $1 \%$ of general population. In Netherlands the overall prevalence of celiac disease was reported to be $0.02 \%$ in adults [5]. An Italian and finnish studies also reported overall prevalence of $1.06 \%$ and $1 \%$ of celiac disease. Various screening studies reported the silent form of celiac disease which is more frequent and results in severe complication in the form metabolic bone disorder or immune conditions if not treated early or delay diagnosis. A reliable and accurate detection is always need of time and is difficult in case of celiac disease because most of the time patients have atypical symptoms which are mild in nature. Antibody levels are measured using ELISA technique by measuring serum anti tTG IgG and IgA level which have been used as a sensitive tool for screening of celiac disease. Various other antibodies such as anti-EM antibody (EMA) and gliadin (AGA) levels are also measured for screening purposes $[6,7]$. There is scarce of literature available on seroprevalence of celiac disease in this part of world, therefore the study was aim to determine the prevalence of Anti tTG in patients having sign symptoms of celiac disease and their pattern in order to reveal age and gender differences.

\section{Materials and Methods}

A cross sectional study was conducted in Rehman medical institute between February-2018 to August-2018. A total of 639 patients having sign symptoms of celiac disease from paediatric and gastroenterology department were included in study irrespective of gender and age. About 3 to $5 \mathrm{ml}$ of blood was collected in a gel vacutainer and centrifuged for obtaining serum. The protocol of study was screening of Anti tTG level using ELISA technology in serum sample on Alegria analyzer. All samples were kept store at $-20 \mathrm{C}$ for other test or for delayed analysis. No samples were reanalyzed after frozen and thawing more than once and check for lipemia and haemolysis. Alegria ELISA technology involves barcoded 8 well microstrips for quantitative determination. Microstrips contain Tetramethylbenzidine (TMB) substrate, sample buffer and enzyme conjugate. Using Sensotronic Memorized Calibration (SMC) Technology, information about assay, calibration, lot specific data are present on barcode on each strip. A value of $>10 \mathrm{IU} / \mathrm{ml}$ for both IgG and IgA level were considered as positive. Quality control procedure also involves 8 well strip having positive sample, enzyme conjugate, substrate and have individual barcode. Data were analyzed using SPSS version 19 and displayed in the form of tables and graphs. Chi square test of association were applied to find out association between the categorical variable and $p$-value of $<0.05$ were considered statistically significant.

\section{Results}

A total of 639 patients were screened for both Anti tTG IgG-IgA level. 57(8.9\%) patients were found positive for both antibodies and 582 patients were negative for both antibodies. Out of 57 positive samples 26 samples were positive for anti tTG-IgG while 31 for anti tTG- IgA as shown in (Table 1).

Out of 381 male 31 were positive for AntitTG while 350 patients were negative. There is no statistical significant 
association found between gender and seroprevelance of AntitTG antibodies. (p:398327 $=>0.05$ ) as shown in (Table 2).

In (Table $3 \& 4$ ) demonstrate difference between age group and Antibody sub type

Table1. Frequency distribution of positive cases
Anti tTG-IgG positive

Anti tTG-IgA positive with no statistical significant relation found for both Anti tTG $\operatorname{IgA}$-IgG and different age groups.

Table 2. Gender wise Anti tTG distribution $(n=639)$

\begin{tabular}{|c|c|c|c|}
\hline Gender & Anti tTG Negative & Anti tTG Positive & $\begin{array}{l}\text { Marginal Row } \\
\text { Totals }\end{array}$ \\
\hline Male & $\begin{array}{lll}350 & (347.01) & {[0.03]}\end{array}$ & $\begin{array}{lll}31 & (33.99) & {[0.26]}\end{array}$ & 381 \\
\hline Female & $\begin{array}{lll}232 & (234.99) & {[0.04]}\end{array}$ & $\begin{array}{lll}26 & (23.01) & {[0.39]}\end{array}$ & 258 \\
\hline $\begin{array}{c}\text { Marginal Column } \\
\text { Totals }\end{array}$ & 582 & 57 & 639 (Grand Total) \\
\hline
\end{tabular}

The chi-square statistic is 0.7134 . The $\mathrm{p}$-value is .398327 . Not significant at $\mathrm{p}<.05$

Table 3. Relationship between Age groups and Anti tTG-IgG

\begin{tabular}{|c|c|c|c|}
\hline Age groups & $\begin{array}{c}\text { AntitTG-IgG } \\
\text { positive }\end{array}$ & $\begin{array}{c}\text { Anti tTG-IgG } \\
\text { Negative }\end{array}$ & Row Totals \\
\hline Age group 1- 20 & $21(18.92)[0.23]$ & $444(446.08)[0.01]$ & 465 \\
\hline Age group 21 - 40 & $4(4.64)[0.09]$ & $110(109.36)[0.00]$ & 114 \\
\hline Age group 41 - 60 & $0(1.71)[1.71]$ & $42(40.29)[0.07]$ & 42 \\
\hline Age group 61 - 80 & $1(0.73)[0.10]$ & $17(17.27)[0.00]$ & 18 \\
\hline Column Total & 26 & 613 & $\mathbf{6 3 9}$ \\
\hline
\end{tabular}

The chi-square statistic is 2.2133 . The $p$-value is .52934 . The result is not significant at $p<.05$

Table 4. Relationship between Age groups and Anti tTG-IgA

\begin{tabular}{|c|c|c|c|}
\hline Age groups & $\begin{array}{c}\text { AntitTG-IgA } \\
\text { positive }\end{array}$ & $\begin{array}{c}\text { Anti tTG-IgA } \\
\text { Negative }\end{array}$ & Row Totals \\
\hline Age group 1 - 20 & $28(22.56)[1.31]$ & $437(442.44)[0.07]$ & 465 \\
\hline Age group 21 -40 & $3(5.53)[1.16]$ & $111(108.47)[0.06]$ & 114 \\
\hline Age group 41 - 60 & $0(2.04)[2.04]$ & $42(39.96)[0.10]$ & 42 \\
\hline Age group 61 - 80 & $0(0.87)[0.87$ & $18(17.13)[0.04]$ & 18 \\
\hline Column Total & 31 & 608 & $\mathbf{6 3 9}$ \\
\hline
\end{tabular}

The chi-square statistic is 5.6555. The $\mathrm{p}$-value is .129628 . The result is not significant at $\mathrm{p}<.05$

\section{Discussion}

Celiac diseases have several clinical presentation ranges from mild, latent, atypical to potential involving predominantly those with predisposing factors. With advancement to availability of diagnostic facilities the prevalence of celiac disease is high comparable to previously thought. The major factor contributed for high prevalence is increase awareness of several clinical manifestation of celiac disease $[8, \mathbf{8}$ ]. Serologic testing using anti tTG have facilitated celiac diagnosis for prompt diagnosis and have higher level of sensitivity and specificity reported [11, 12]. European society of paediatric gastroenterology and Nutrition also recommend immunological markers for celiac disease diagnosis in order to limit the intervention of intestinal biopsies if $\mathrm{tTg} \operatorname{IgA}>10$ times upper limit of normal 
along with concordant agreement of family [13].

In our study the overall prevalence of celiac disease were $8.9 \%$. A similar study conducted by Saberi-Firouzi, et al. [14] reported overall prevalence of $0.5 \%$ (1:180) which is low comparable to our finding. Their high sample size may contribute for low prevalence. Study conducted in northern and southern Iran on gluten sensitive enteropathy reported 29 cases positive for Anti tTG antibody Gursoy et al. [15] reported $1.76 \%$ prevalence of celiac disease. Gursoy et al. [6] however another study from turkey reported similar prevalence of $8.3 \%$ in those having predisposing factor such as short stature using endoscopic small intestinal biopsy respectively. Muhammad et al. [16] also reported similar finding of $7.1 \%$ overall prevalence of celiac disease. The serological diagnosis have importance in detection of celiac disease using different immunological markers however the true prevalence will not revealed until subjected to histopathological findings.

Similar finding were also reported by Pakistani study [17] with a prevalence of $11.7 \%$ for anti tTG IgA antibodies with predominance of higher prevalence in children. Our study also shows a similar pattern of age related seroprevelance with higher frequency found in age group 1-20 years respectively. This shows a concordant pattern of prevalence in this geographical area of world.

Infancy and childhood may contribute for larger prevalence of celiac disease. Our finding also revealed lower prevalence of adulthood and higher frequency of childhood disease. Various studies reported higher percentage of childhood disease distribution and decrease percentage stated in adulthood. [17, 18] We found higher seroprevelance of Anti tTG IgA compared to AntitTG IgG. Similar finding were also reported by Gillet et al. [19].

Anti-tTG IgA-IgG contribute significantly in immunological detection of celiac disease however other specific immunological markers such as antiendomysial antibody and small intestinal biopsy remains gold standard for staging ,grading of disease and to rule out false positive result associated with other autoimmune pathologies. In our setting gluten is present in mostly edible food and only therapeutic strategy is prevention from diet containing gluten. A larger scale study is needed for revealing of economic burden contribute by gluten free diet and to figure out the true histopathological characteristics of celiac disease with respect to its grading.

\section{Conclusion}

We conclude that anti tTG- Antibody is high in childhood as compared to other age groups. Gender revealed no significant association with seroprevelance of disease. Serological along with histopathological investigations may contribute accurate and more reliable diagnosis.

\section{Authors' contributions}

Conceived and designed the experiments: S Ahmad, NA Gill \& F ullah, Performed the experiments: NA Gill \& F Ullah, Analyzed the data: S Ahmad, N Ali, M Afridi, N Ahmad, NQ Ahmad \& I Naz, Contributed materials/ analysis/ tools: S Ahmad, NA Gill, N Ahmad, NQ Ahmad, N Ali \& I Naz, Wrote the paper: S Ahmad.

\section{References}

1. Murray JA, Watson T, Clearman B \& Mitros F (2004). Effect of a glutenfree diet on gastrointestinal symptoms in celiac disease. The Am J of ClinNutr 79(4): 669-673.

2. Dickey W \& Kearney N (2006). Overweight in celiac disease: prevalence, clinical characteristics, and effect of a gluten-free diet. Am J of Gastro 101(10): 2356-2359.

3. Wolters VM \& Wijmenga C (2008). Genetic background of celiac disease and its clinical implications. Am J of Gastro 103(1): 190-195.

4. Abu Zekry, M Kryszak, D Diab, M Catassi C \& Fasano A (2008). Prevalence of celiac disease in 
egyptian children disputes the east west agriculture-dependent spread of the disease. $J$ of Pedi Gastro \& Nut 47(2): 136-140.

5. Jong KD, Jaddoe JC, Uitterlinden VWV, Steegers AG, Willemsen EAP, Hofman SP, Hooijkaas H \& Moll, HA. (2013) Levels of antibodies against tissue transglutaminase during pregnancy are associated with reduced fetal weight and birth weight. Gastro 144(4): 726-735

6. Gursoy S, Guven K, Simsek T, Yurci A, Torun E, Koc N et al. (2005). The prevalence of unrecognized adult celiac disease in Central Anatolia. $J$ of Clin Gastro 39(6): 508-511.

7. Sacchetti L, Ferrajolo A, Salerno G, Esposito P, Lofrano MM, Oriani G et al. (1996) Diagnostic value of various serum antibodies detected by diverse methods in childhood celiac disease. Clin Chem 42(11): 1838-1842.

8. Tursi A, Giorgetti G, Brandimarte G, Rubino E, Lombardi D \& Gasbarrini G. (2001) Prevalence and clinical presentation of subclinical/silent celiac disease in adults: an analysis on a 12-year observation. Hepato-Gastro 48(38): 462-464.

9. Biagi F \& Corazza GR. (2002) Clinical features of coeliac disease. Dig \& Liver Dis 34(3): 225-228.

10. Tursi A, Brandimarte $G$ \& Giorgetti GM (2003) Prevalence of Antitissue Transglutaminase Antibodies in Different Degrees of Intestinal Damage in Celiac Disease. $J$ of clin Gastro 36(3): 219-221.

11. Biagi F, Ellis HJ, Yiannakou JY, Brusco G, Swift GL, Smith PM et al. (1999) Tissue transglutaminase antibodies in celiac disease. The American J of Gastro 94(8): 21872192.

12. Sblattero D, Berti I, Trevisiol C, Marzari R, Tommasini A \& Bradbury A et al. (2000) Human recombinant tissue transglutaminase ELISA: an innovative diagnostic assay for celiac disease. The American $J$ of Gastro 95(5): 1253-1257.

13. Husby S, Koletzko S, KorponaySzabó I, Kurppa K, Mearin ML \& Ribes-Koninckx C et al. (2020) European society paediatric gastroenterology, hepatology and nutrition guidelines for diagnosing coeliac disease 2020. J of Pedi Gastro and Nut 70(1): 141-156.

14. Saberi-firouzi M, Omrani GR, Nejabat M \& Mehrabani D (2008) Prevalence of Celiac Disease in Shiraz, Southern Iran. Offi J of the Saud Gastro Assoc 14(3): 135-138.

15. Akbari MR, Khani AM, Fakheri H, Zahedi MJ, Shahbazkhani B \& Nouraie M et al. (2006) Screening of the adult population in Iran for coeliac disease: comparison of the tissuetransglutaminase antibody and antiendomysial antibody tests. Euro $J$ of Gastro \& Hepato 18(11): 1181-1186.

16. Tumer L, Hasanoglu A \& Aybay C. (2001) Endomysium antibodies in the diagnosis of celiac disease in shortstatured children with no gastrointestinal symptoms. Pedia Interna: Offi J of the Japan Pediatric Soc 43(1): 71-73.

17. Jamila, Kiani RA, Ahmed I, Yousafzai JK \& Mehmood W et al. (2018) Celiac Disease in Different Age Groups and Gender in Pakistan. $J$ of Rawal Med colleg 22 (3): 244-247.

18. Marine M, Farre C, Alsina M, Vilar P, Cortijo M \& Salas A et al. (2011). The prevalence of coeliac disease is significantly higher in children compared with adults. Alimen Pharma \& Therap 33 (4): 477-486.

19. Gillett HR, Cauch-Dudek K, Healthcote EJL \& Freeman HJ. (2000) Prevalence of IgA antibodies to endomysium and tissue transglutaminase in primary biliary cirrhosis. Cana J of Gastro \& Hepat 14(8): 672-675. 